\title{
The best of both worlds - Nu Sapphire Dual-Path MC-ICP-MS for routine high precision strontium isotope determination
}

\author{
YE ZHAO $^{1}$, PATRIC SIMOES PEREIRA $^{2}$, TINA VAN DE \\ FLIERDT $^{2}$ AND MARK REHKÄMPER ${ }^{2}$ \\ ${ }^{1}$ Ametek, Inc. \\ ${ }^{2}$ Imperial College London \\ Presenting Author: ye.zhao@ametek.com
}

Strontium ( $\mathrm{Sr}$ ) isotopes are widely studied for environmental tracing, geochronological and archaeological purposes. Although commonly used for high precision $\mathrm{Sr}$ isotope measurements, Multi-collector ICP-MS (MC-ICP-MS) instruments are often associated with accuracy issues related to $\mathrm{Kr}$ and $\mathrm{Rb}$ interference corrections, and baseline scatter caused by the large ${ }^{40} \mathrm{Ar}^{40} \mathrm{Ar}^{+}$ beam. Therefore, the more traditional Thermal Ionization Mass Spectrometry (TIMS) technique is still widely regarded by academic laboratories as the gold standard for precise and accurate $\mathrm{Sr}$ isotopic analysis.

$\mathrm{Nu}$ Sapphire, a new generation MC-ICP-MS instrument equipped with a dual-path design, consisting of a conventional MC-ICP-MS pathway and a collision/reaction cell pathway, was tested for $\mathrm{Sr}$ isotope analysis in this study. The instrument inherits high energy extraction from the Plasma 3 instrument and thus retains high sensitivity in both modes. The application of the collision/reaction cell brings substantial benefits to routine $\mathrm{Sr}$ isotope measurements, as it enables efficient removal of both the $\mathrm{Kr}$ interferences and the large ${ }^{40} \mathrm{Ar}^{40} \mathrm{Ar}^{+}$ion beam, whilst maintaining the high sensitivity and throughput of a conventional MC-ICP-MS. Rb, the other potential interference, was separated from the samples using standard chromatography prior to the mass spectrometry.

In this study, we demonstrate that after carefully setting up the collision/reaction cell, it is possible to apply the exponential law for fractionation correction to obtain accurate and precise $\mathrm{Sr}$ isotope data. Various geological and biological samples (silicate rocks and minerals, sediments and organic materials, including bones and teeth) were analysed both with the $\mathrm{Nu}$ Sapphire and the TIMS (at Imperial College London) following digestion and separation of Sr using a one-step column chemistry procedure.

The identical results obtained on both instruments verify in detail that the Sapphire can indeed be used for high precision $\mathrm{Sr}$ isotope determination of samples from a wide range of backgrounds with minimal matrix effect, and produce results identical to the TIMS, but with lower sample consumption and higher throughput. The results thus establish the Sapphire not only as a unique instrument to explore isotope systems previously unaccessible, but also as a laboratory workhorse that can tackle all the tasks that conventional TIMS and MC-ICP-MS are expected to handle. 